\title{
Exacerbation of well-controlled bullous pemphigoid by the administration of a dipeptidyl peptidase-4 inhibitor
}

C. Nishiyama, C. Tateishi, T. Hashimoto, M. Nishida, A. Imanishi, T. Shiratori, N. Maekawa, D. Tsuruta, K. Fukai

\begin{tabular}{|c|l|}
\hline Citation & Clinical and Experimental Dermatology. 44(7); 830-832 \\
\hline Issue Date & $2019-10$ \\
\hline Version of Record & 2019-04-10 \\
\hline Type & Journal Article \\
\hline Textversion & Author \\
\hline Rights & $\begin{array}{l}\text { This is the peer reviewed version of the following article: Clinical and } \\
\text { Experimental Dermatology, Vol.44, Issu.7, p.830-832., which has been } \\
\text { published in final form at https://doi.org/10.1111/ced.13962. This article } \\
\text { may be used for non-commercial purposes in accordance with Wiley Terms } \\
\text { and Conditions for Use of Self-Archived Versions. }\end{array}$ \\
\hline DOI & \begin{tabular}{l} 
10.1111/ced.13962 \\
\hline
\end{tabular} \\
\hline
\end{tabular}

\author{
Self-Archiving by Author(s) \\ Placed on: Osaka City University
}

NISHIYAMA, C., TATEISHI, C., HASHIMOTO, T., NISHIDA, M., IMANISHI, A., SHIRATORI, T., MAEKAWA, N., TSURUTA, D., \& FUKAI, K. (2019). Exacerbation of well-controlled bullous pemphigoid by the administration of a dipeptidyl peptidase-4 inhibitor. Clinical and Experimental Dermatology. 44, 830-832. Doi:10.1111/ced.13962 
Exacerbation of well-controlled bullous pemphigoid by the administration of a dipeptidyl peptidase-4 inhibitor: a case report

C. Nishiyama, ${ }^{1}$ C. Tateishi, ${ }^{2}$ T. Hashimoto,${ }^{2}$ M. Nishida, ${ }^{1}$ A. Imanishi, ${ }^{1}$ T. Shiratori, ${ }^{1}$ N. Maekawa, ${ }^{1}$ D. Tsuruta, ${ }^{2}$ K. Fukai ${ }^{1}$

1Department of Dermatology, Osaka City General Hospital, Osaka, Japan 2Department of Dermatology, Osaka City University Graduate School of Medicine, Osaka, Japan

Correspondence: Kazuyoshi Fukai, MD

Department of Dermatology, Osaka City General Hospital, Osaka, Japan

2-13-22, Miyakojimahondori, Miyakojima-ku, Osaka 534-0021, JAPAN

TEL +81-6-6929-1221

FAX +81-6-6929-3341

E-mail fukai@msic.med.osaka-cu.ac.jp

Word count:489 
The incidence of bullous pemphigoid is increasing recently, partly due to the increase of the use of certain culprit drugs, such as dipeptidyl peptidase-4 (DPP4) inhibitors, psychotropic drugs, and checkpoint-inhibitors. ${ }^{1}$ DPP-4 inhibitors, a class of oral hypoglycemics, block the enzyme dipeptidyl peptidase-4, and can be used to treat diabetes mellitus type 2 . Association of bullous pemphigoid and mucous membrane pemphigoid with DPP-4 inhibitors in patients with diabetes has been recently demonstrated. ${ }^{2,}{ }^{3}$ Bullous pemphigoid associated with DPP4 inhibitors (DPP4i-BP) tends to show clinically non-inflammatory phenotypes and be negative for the BP180 NC16A domain, but positive for full-length BP180. ${ }^{4}$ On the other hand, several cases of DPP4i-BP have been reported to be positive for anti-BP180 NC16A domain antibodies and show inflammatory phenotypes with prominent erythemas. ${ }^{5}$

A 90-year-old Japanese man was referred to us for evaluation of itchy blistering skin lesions on the limb and trunk that had developed one month before. He had been diagnosed with mild diabetes mellitus for 30 years, which had been untreated. At the first visit to our hospital, chemiluminescent enzyme immunoassay (CLEIA) was positive for anti-BP180 NC16A antibodies (265.3 $\mathrm{U} / \mathrm{ml}$, with the standard normal value of $<9 \mathrm{U} / \mathrm{ml}$ ). Histopathology of the skin 
biopsy from a bulla demonstrated subepidermal blister with infiltrates of eosinophils. Direct immunofluorescence analysis showed a linear deposition of complement $\mathrm{C} 3$ at the basement membrane zone. We diagnosed the patient with bullous pemphigoid and started treatment with prednisolone $30 \mathrm{mg} /$ day $(0.44$ $\mathrm{mg} / \mathrm{kg} /$ day) and minocycline $200 \mathrm{mg} /$ day. Ten months after the first visit, when the skin condition was stable with prednisolone $8 \mathrm{mg} /$ day, sitagliptin, a member of the DPP-4 inhibitors, was started by the patient's primary care doctor. One month later, multiple infiltrative erythemas, erosions, and blisters developed on the entire body (Fig. 1). The anti-BP180 NC16A antibody titer elevated to 538.2 $\mathrm{U} / \mathrm{ml}$. We stopped the administration of sitagliptin and started treatment with prednisolone $35 \mathrm{mg} /$ day and minocycline $100 \mathrm{mg} /$ day. Despite this, new blisters appeared and erythemas continued; then, we started intravenous immunoglobulin therapy (30 g/day; $0.44 \mathrm{mg} / \mathrm{kg} / \mathrm{day}$, for 5 days). The skin lesions gradually improved with a decrease in the titers of anti-BP180 NC16A domain antibodies. However, although the dose of steroid was tapered, the skin lesions were refractory and could not be completely suppressed. Unfortunately, after 37 weeks after the exacerbation by sitagliptin, the patient developed sepsis with disseminated intravascular coagulation and finally passed away from multiple 
organ failure. The whole disease course of this case is illustrated in Fig. 2.

In the present case, bullous pemphigoid that had been stable with a low dose of steroid showed exacerbation of exanthemas with a rapid rise in the level of anti-BP180 NC16A autoantibodies one month after administration of a DPP-4 inhibitor. To our knowledge, such cases have never been reported. DPP-4 inhibitors are generally safe and can be used even for elderly patients with diabetes mellitus. In bullous pemphigoid cases, particular care is required in the selection of the drugs for diabetes mellitus. 


\section{REFERENCES}

1) Kridin K, Ludwig RJ. The growing incidence of bullous pemphigoid: overview and potential explanations. Front Med (Lausanne) 2018; 5:220.

2) Kridin K, Bergman R. Association of bullous pemphigoid with dipeptidylpeptidase 4 inhibitors in patients with diabetes: estimating the risk of the new agents and characterizing the patients. JAMA Dermatol 2018; 154:11521158.

3) Gaudin O, Seta V, Alexandre M, et al. Gliptin accountability in mucous membrane pemphigoid induction in 24 Out of 313 patients. Front Immunol 2018; 9:1030.

4) Izumi K, Nishie W, Mai $Y$ et al. Autoantibody profile differentiates between inflammatory and noninflammatory bullous pemphigoid. J Invest Dermatol 2016; 136: 2201-2210.

5) Mai Y, Nishie W, Izumi K et al. Detection of anti-BP180 NC16A autoantibodies after the onset of dipeptidyl peptidase-IV inhibitor-associated bullous pemphigoid: a report of three cases. $B r J$ Dermatol 2018; 179: 790-791 
Figure legends

Figure 1: Exudative erythemas with blisters and erosions on the thighs. 


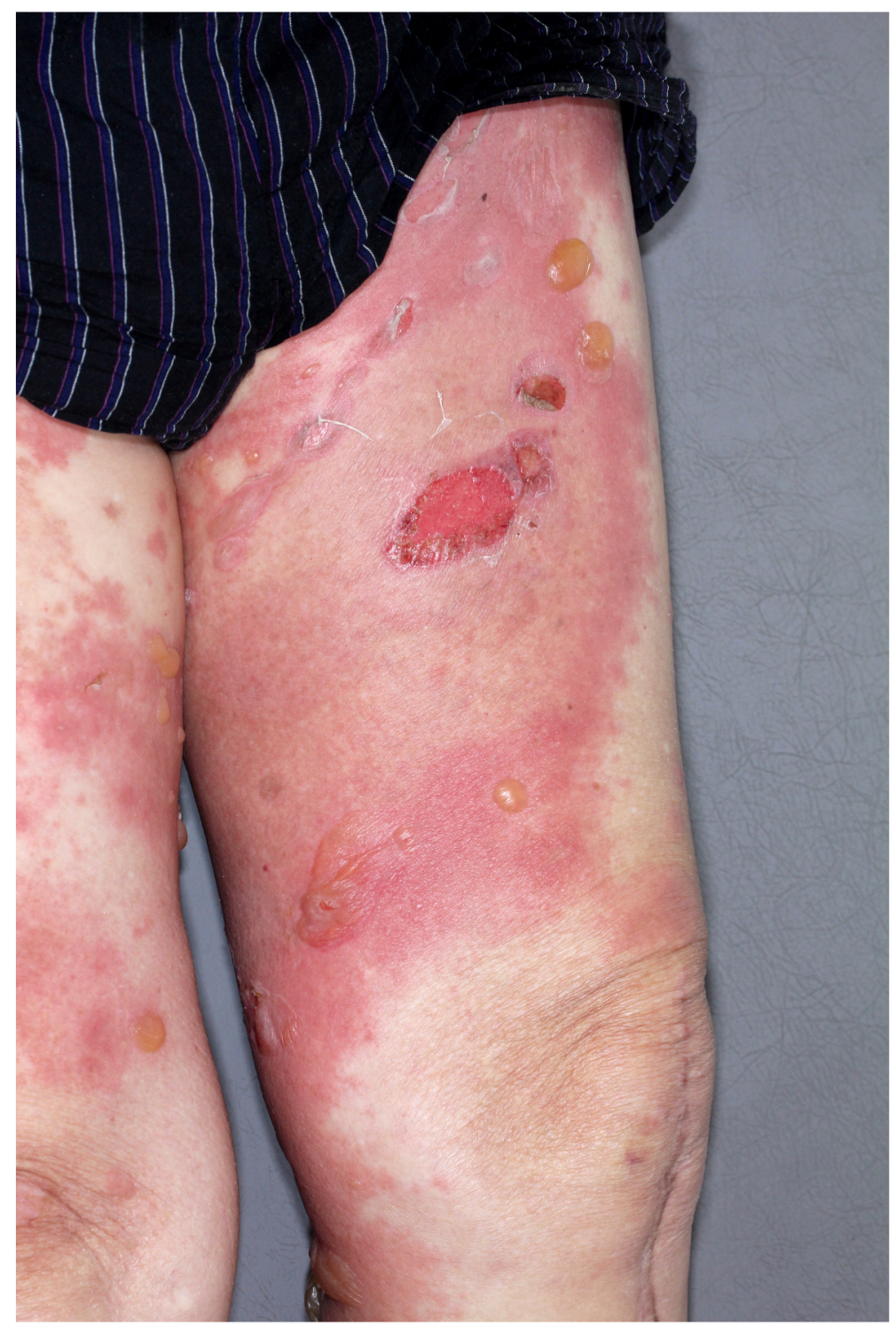

Figure.1 
Figure 2: The time-courses of the treatments, the skin conditions, and the antiBP180 NC16A antibody titers. The period of the administration of the DPP-4 inhibitor, sitagliptin, is indicated by a red square. The doses of prednisolone are shown by green bars, anti-BP180NC16A titers by blue bars, and the skin conditions (BPDAI) by a brown line. 


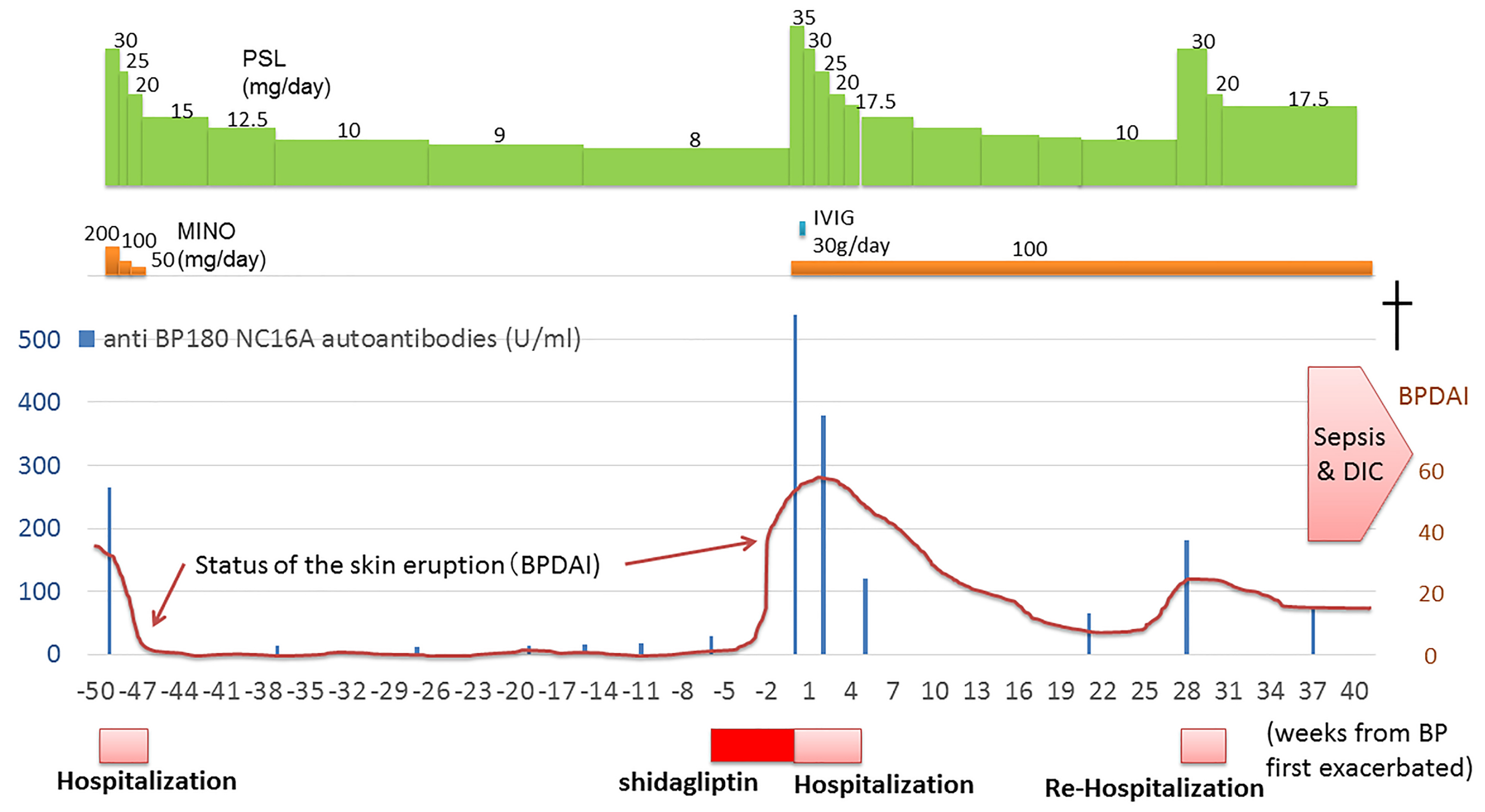

Figure.2 